\title{
An update on the cause and treatment of sleep disturbance in children and adolescents with autism spectrum disorder
}

\author{
Wan Seok Seo \\ Department of Psychiatry, Yeungnam University College of Medicine, Daegu, Korea
}

Received: August 6, 2021

Revised: August 25, 2021

Accepted: August 25, 2021

Corresponding author: Wan Seok Seo, MD, PhD Department of Psychiatry, Yeungnam University College of Medicine, 170 Hyeonchung-ro, Nam-gu, Daegu 42415, Korea

Tel: +82-53-620-3340

Fax: +82-53-657-3921

E-mail: sws3901@ynu.ac.kr

\begin{abstract}
Autism spectrum disorder (ASD) is a neurodevelopmental disorder characterized by abnormalities in social communication/interaction and restrictive, repetitive patterns of behavior. ASD is a relatively common psychiatric disorder, with a prevalence of approximately $1.7 \%$ in children. Although many children and adolescents with ASD visit the hospital for medical help for emotional and behavioral problems such as mood instability and self-harming behavior, there are also many visits for sleep disturbances such as insomnia and sleep resistance. Sleep disturbances are likely to increase fatigue and daytime sleepiness, impaired concentration, negatively impact on daytime functioning, and pose challenges in controlling anger and aggressive behavior. Sleep disturbance in children and adolescents with ASD negatively affects the quality of life, nothing to say the quality of life of their families and school members. In this review, sleep disturbances that are common in children and adolescents with ASD and adolescents are presented. The developmental and behavioral impacts of sleep disturbances in ASD were also considered. Finally, non-pharmacological and pharmacological treatments for sleep disturbances in children and adolescents with ASD and adolescents are reviewed.
\end{abstract}

Keywords: Autism spectrum disorder; Insomnia; Melatonin; Problem behavior; Sleep

\section{Introduction}

Autism spectrum disorder (ASD) is a common neurodevelopmental disorder with a prevalence of approximately $1.7 \%$ in the general population. ASD is a disease with abnormalities in two domains: social communication/interaction and restrictive, repetitive patterns of behavior [1]. ASD is a multi-genetic disorder with a strong genetic tendency, occurring about four times more in men than in women, which is postulated to be related to a female protective effect [2].

Many ASD symptoms begin early in life and persist throughout life. Typical ASD symptoms include internalizing problems such as anxiety, depression, somatization, and externalizing problems such as rule-breaking, aggression, self-harm, hyperactivity, impulsivity, and core deficits. These ASD symptoms have a significant negative impact on the quality of life, and that of their families and school members. Therefore, ASD has a significant impact on public health and education systems [3].

Sleep is an important physiological phenomenon for typical synaptic development and brain maturation, and children with sleep disturbances are vulnerable to emotional and cognitive development [4]. In particular, rapid eye movement sleep disturbance is associated with neural maturation and organization difficulties in children with ASD [5]. Sleep disturbances of children and adolescents with ASD are necessary to recognize and treat actively as they persist for a long time, and can change the sleeping patterns of

Copyright (C) 2021 Yeungnam University College of Medicine

This is an Open Access article distributed under the terms of the Creative Commons Attribution Non-Commercial License (http://creativecommons.org/licenses/by-nc/4.0/) which permits unrestricted non-commercial use, distribution, and reproduction in any medium, provided the original work is properly cited. 
parents and siblings sharing the same living space [6].

The causes, impact on daytime activity, evaluation, and treatment of sleep disturbance in children and adolescents with ASD were reviewed.

\section{Are sleep disturbances common in children and adolescents with autism spectrum disorder?}

Sleep disturbance in children and adolescents with ASD is the most agonizing symptom for parents and one of the primary reasons for seeking psychiatric assistance [7]. Commonly, the prevalence of sleep disturbance in children and adolescents with ASD is approximately $60 \%$ to $86 \%$, which is 2 to 3 times that of typically developed children [8]. Their sleep disturbances are not related to the level of cognitive and language development.

There are many different types of sleep disturbances. Difficulty in sleep onset and maintenance, decreased total sleep time (TST), frequent night waking, bedtime resistance, excessive daytime sleepiness, and behavioral insomnia in childhood are common [911]. In studies using actigraphy and polysomnography, children with ASD reported shorter sleep time, longer sleep latency (SL), and decreased sleep efficiency (SE) compared with typically developed children [12].

\section{Does sleep disturbance affect behavior and emotional regulation, and daytime functioning in children and adolescents with autism spectrum disorder?}

There is growing interest in the relationship between sleep disturbance and daytime problem behavior in children and adolescents with ASD $[9,10]$. Sleep disturbance in children and adolescents with ASD negatively affects daytime functioning, including behavioral control, learning function and memory, and leads to increased stress levels in their family members $[9,13]$. Poor sleep has been linked to increase internalizing and externalizing problems, including tantrums, oppositional behavior, physical aggression, irritability, self-injury, depression, anxiety, mood variability, inattention, and hyperactivity [9,14-16].

The effect on internalizing and externalizing problems varies depending on the degree and type of sleep disturbances. Adams et al. [16] reported that externalizing and overall problem behaviors were highly correlated with the severity of sleep problems, but not with internalizing behaviors. Meanwhile, Sikora et al. [15] suggested that both severe internalizing and externalizing problems were related only to moderate to severe sleep disturbance. In a study of
40 male children with ASD (aged 5-12 years), there was a positive relationship between the severity of ASD symptoms and problem behavior in patients with no or mild sleep disturbance, while there was no significant relationship between the severity of ASD symptoms and problem behavior in patients with moderate-to-severe sleep disturbance [17]. In a polysomnography study of 21 children with ASD, Malow et al. [18] reported that poor sleepers had more affective and social problems, and Goldman et al. [19] reported that sleep fragmentation was correlated with restricted and repetitive behavior. In addition, aggression, self-injury, and tantrum can be predicted when there is a night-to-night variation in sleep onset time and sleep duration [20].

However, the effect of the type or severity of sleep disturbances on the severity of core symptoms, externalization, and internalization symptoms of ASD is still unclear, and further studies are needed to address this issue.

\section{Causes of sleep disturbance in children and adolescents with autism spectrum disorder}

The causes of sleep disturbance in children and adolescents with ASD have not been clearly identified. Sleep disturbance is correlated with biological, psychological, and social/environmental factors. Abnormalities in melatonin synthesis, hypersensitivity to environmental stimuli, behavioral insomnia in childhood, delayed sleep phase syndrome, rapid eye movement sleep behavior disorder, and accompanying neurological and psychiatric disorders such as anxiety, depression, and epilepsy are considered as the main causes. Additionally, neurophysiological and neurochemical abnormalities, abnormal timing of melatonin secretion, comorbid medical conditions and current medications, core ASD symptoms, child-rearing practices, and family stress have been suggested as causes of sleep disturbance [13]. Sleep disturbance becomes apparent by the underlying biological and behavioral rhythm problems, which are triggered by internal and external stress [21-23].

In this section, environmental and behavioral problems, arousal and sensory dysregulation, circadian-relevant gene abnormalities, melatonin rhythm, peak and receptor site abnormalities, and comorbid psychiatric disorders, which are the main causes of sleep disturbance in children and adolescents with ASD, are reviewed.

\section{Environmental and behavior problems}

Learned behaviors are suggested to be one of the most common causes of delayed sleep onset and night waking. Many children and adolescents with ASD have a delayed sleep onset and difficulty falling asleep due to increased screen time in video games, mobile 
games, and others [24]. In a study on the association between bedroom media access and sleep disturbance in 49 pediatric patients with ASD, it was reported that media-related variables were associated with sleep disturbance in children with ASD [25]. Sleep in children has a bidirectional relationship with parent sleep. It is important to evaluate the parents' sleep problems, mental health, and parental stress together when evaluating a child's sleep disturbance [26]. Parents who are vulnerable to stress, and anxious or depressed parents are more likely to create a negative environment for children's sleep [27]. Maternal autism traits and anxiety, lower family income, and lower paternal education were also related to their sleep disturbances [26]. Lower family income creates a negative socioeconomic environment for children with ASD, exposing them to more disruptive sleep conditions, which can worsen sleep quality.

\section{Arousal and sensory dysregulation in insomnia}

There is increasing evidence that sleep disturbance in children and adolescents with ASD is related to arousal dysregulation and sensory hyper-reactivity and that a calming strategy is needed to improve their sleep. Increased cognitive activity, such as having considerable thoughts and worries in bed, makes it difficult to initiate sleep [28]. Physiological arousal is also associated with insomnia. Patients with insomnia have high levels of sympathetic activity, which results in high levels of heart rate, body temperature, and heart rate variability, and is related to high levels of norepinephrine (NE) activity $[29,30]$.

The hyper-arousal response in some children with ASD is related to dysfunction of the locus coeruleus (LC)-NE system. When LC is in phasic mode, individuals generally respond to sensory stimuli and perform appropriate tasks through focused attention. However, when the NE release state in the LC becomes a high tonic state, it cannot respond appropriately to the stimulus and becomes a hyper-arousal state [31]. Children with ASD in this state have inattentiveness, impulsivity, hyperactivity, anxiety, panic, and sleep disturbance. Additionally, children with ASD experience a "hyper-arousal state" associated with abnormal interactions between the two systems, sympathetic hyper-arousal or parasympathetic hypo-arousal, which is associated with anxiety, fear, worry, and insomnia due to sensitivity to environmental stimuli [21].

Hypersensitivity to certain sensory stimuli is also associated with sleep disorders in children and adolescents with ASD. In a study of 27 children aged 6 to 12 years with ASD and 27 typically developed children, children with ASD had more atypical sensory behaviors and sleep disturbances than typically developed children [32]. Children with ASD overreact to certain stimuli as they have a low sensory threshold, and this is related to difficulty initiating or maintaining sleep [33].

\section{Circadian relevant gene abnormality}

Some researchers suggest that clock genes such as human PER1 (hPER1), hPER2, and hPER3, and clock gene-gene interaction may affect not only human sleep but also human social communication and brain development [34]. Genes related to synaptic homeostasis are involved in synaptic development and pruning, as well as mechanisms involved in sleep-wake control [35]. A recent study reported that acetylserotonin $\mathrm{O}$-methyltransferase and variation in cytochrome P450 1A2 in ASD are related to sleep disturbance [36].

4. Melatonin rhythm, peak, and receptor site abnormalities Melatonin is synthesized in the pineal gland and regulated by MTNR1A and MTNR1B receptors in the suprachiasmatic nucleus and is involved in the initiation and maintenance of sleep, regulation of seasonal cycles, and immune function [37]. Melatonin is closely related to circadian rhythm, and circadian misalignment is related to abnormal melatonin synthesis, altered melatonin secretion patterns, circadian clock gene anomalies [38].

Insomnia in children with ASD is suggested to be related to abnormal melatonin levels [39]. Abnormal production, increased breakdown, and receptor site abnormalities of melatonin induce an increase in SL and night wakening. Patients with ASD have low levels of melatonin and low urine, serum, or plasma levels of melatonin metabolite, urinary 6-sulfatoxymelatonin [22,40,41]. In ASD children with sleep disturbance, low melatonin levels appear to be related to mutations in genes related to the melatonin synthesis pathway.

\section{Comorbid psychiatric disorders}

Children with ASD are more likely to have attention deficit hyperactivity disorder (ADHD) and anxiety disorders, which are considered high-arousal disorders $[42,43]$. In a study comparing the mean electrodermal activity (EDA) and electrodermal reaction frequency of two groups by anxiety level (low and high), the mean EDA for the high anxiety group was significantly lower than that of the control and low anxiety groups, suggesting an abnormality in sympathetic activity in children with ASD [44].

Comorbid medical disorders such as epilepsy, asthma, allergies, gastroesophageal reflux diseases (GERDs), and psychiatric disorders such as anxiety, depression, bipolar disorder, psychosis, and $\mathrm{ADHD}$ can negatively affect sleep in children and adolescents with ASD $[1,26]$. Additionally, intellectual disability, sensory integration deficits, ritualistic or self-injurious behaviors, poor communication skills, and limited responsiveness to social cues can interfere 
with sleep training and can exacerbate sleep disturbance.

\section{Evaluation of sleep disturbance}

The evaluation of children and adolescents with ASD with sleep disturbance should include sleep-related history taking, evaluation of sleep environment, and comorbidities. Sleep environment evaluation includes household noise, noise between floors, parental working hours, bedtime routines, and history of comorbid medical conditions that might disrupt sleep, such as GERD, seizures, asthma, allergies, eczema, or enuresis [1].

Sleep questionnaires are often used to evaluate sleep disturbances in children with ASD. They can evaluate sleep disturbance relatively objectively, are easy to apply, and do not require much time, money, and expertise [45].

The Children's Sleep Habits Questionnaire (CSHQ) consists of a three-point Likert scale that allows parents to develop behavioral and physiological sleep disorders in school-age children. CSHQ is a screening tool to measure overall sleep characteristics and disturbances in children, including bedtime resistance, sleep onset delay, sleep anxiety, night waking, parasomnia, sleep-disordered breathing, and daytime sleepiness [46]. It comprises 27 questions in eight domains, sleep resistance (six questions), sleep onset delay (one question), amount of sleep (three questions), sleep anxiety (four questions), wakefulness after sleep onset (three questions), parasomnia (seven questions), sleep breathing disorder (three questions), and daytime sleepiness (eight questions).

The Aberrant Behavior Checklist can evaluate the severity of problem behaviors: irritability, agitation, and crying, lethargy, social withdrawal, stereotypic behavior, hyperactivity, noncompliance, inappropriate speech, and sleep problems in children with developmental delay [47].

Some children with ASD with restless sleep and night waking may require laboratory tests, such as ferritin levels, to evaluate iron stores [48].

\section{Management and treatment}

\section{Non-pharmacological management}

Environmental and behavioral strategies are needed to control sleep disturbances in children and adolescents with ASD. Parents need to create a bedroom environment and form bedtime routines to calm down their children. Although these environmental and behavioral strategies are not easy to set up, they can positively alter sleep in children with ASD if performed consistently [49]. The sleep tool kit (STK), developed by the Sleep Committee of the Autism Treatment Network, is a tailored behavioral intervention tool for children and adolescents with insomnia [49]. STK recommends three methods: visual scheduling of positive evening behaviors, a supplemental calming module to lower arousal levels, and a faded bedtime protocol to go to bed when sleepy. Supplementary calming modules include breathing techniques, muscle relaxation techniques, yoga, massage, mindfulness exercises, and warm baths, which help to control arousal and anxiety in children with ASD [49]. Considering the developmental characteristics of children with ASD, unmodified and graduated extinction, positive routines, and bedtime fading are more effective in children under 5 years of age; however, cognitive-behavioral therapy (CBT) is more beneficial in older children and adolescents [50].

Parent-based sleep education (PSE) has been introduced and used to solve sleep problems in children with ASD and adolescents. PSE is a four-page pamphlet designed to help children with sleep disturbances and is available at www.autismspeaks.org. PSE includes creating a stable sleep environment, regular sleep habits and lifestyle, educating a child to sleep alone, avoiding naps, and facilitating daytime activities. However, the positive effects of PSE on sleep have not yet been demonstrated. A randomized study of 36 children (aged 2-10 years) with SL of 30 minutes into two groups reported that the pamphlet-based education group $(n=19)$ did not significantly improve SL compared with the group that did not $(\mathrm{n}=17)$ [14]. In a study using actigraphy and CSHQ on the effect of individual training and group training for 80 children with ASD aged 2 to 10 years, the difference in outcome according to the mode of education was not significant [49].

Weighted blankets are heavy blankets used commercially to reduce anxiety and insomnia, and some parents with ASD prefer to use weighted blankets for their children. The National Autistic Society also notes that some children may benefit from sleep with a weighted blanket. However, weighted blankets did not have a significantly positive effect on sleep in children and adolescents with ASD. In a 10-month randomized, placebo-controlled crossover study of 73 children and adolescents with ASD (aged 5-16 years), the difference in TST and SL between the group using weighted blankets and the group using control blankets was not significant [51].

Sound-to-sleep (STS) mattresses are manufactured in such a way that specific sounds and vibrations are implanted in the mattress. The use of STS mattress technology can reduce bedtime resistance by allowing children to feel their favorite sounds and vibrations in bed. In a study of 45 children with ASD (aged 2.5-12.9 years), sleep duration and sleep efficiency were improved after 2 weeks of STS mattress use, although there was no significant decrease in SL [52]. 


\section{Pharmacological management}

To date, no medication has been approved for the treatment of insomnia in children with ASD so far in Korea that is the same as in the United States. When using medications to solve sleep disturbance in children with ASD, it should be initiated with small doses and the side effects of medications should be considered [53]. Some medications used in clinical settings to control sleep disturbance in children with ASD have been introduced.

Melatonin is one of the most commonly used drugs to control sleep problems in children and adolescents with ASD. Melatonin is known to have a positive effect on reducing SL, lowering sleep resistance, and increasing TST. In 125 children and adolescents (aged 2-17.5 years) with ASD who had sleep disturbance lasting more than 3 months and did not affect behavioral therapy for 4 weeks, TST was increased by 57.5 minutes, and SL was decreased by 39.6 minutes when 2 to $5 \mathrm{mg}$ of melatonin mini-tablets were administered for 13 weeks [54]. In a study of 160 children with ASD (aged 4-10 years), $3 \mathrm{mg}$ of melatonin was also helpful in lowering insomnia symptoms and bedtime resistance [55]. In a meta-analysis of 35 studies including five randomized double-blind and placebo-controlled studies, melatonin increase TST by 73 minutes and decrease SL by 66 minutes from baseline [56]. Some children have reported nightmares when using melatonin. However, the side effects of melatonin are uncommon and mild.

Alpha-adrenergic agents (clonidine) and antihistamines (diphenhydramine) are also used to ameliorate prolonged sleep onset and frequent night-waking, although research evidence is weak [57].

Low-dose quetiapine is used to improve sleep disturbance and control problem behaviors such as aggression and irritability in children with ASD. In an 8-week open-label study of 18 patients (aged 13-17 years), quetiapine significantly improved their aggression and sleep disturbance [58]. However, special caution is required as atypical antipsychotics, including quetiapine, may cause restless legs syndrome in cytochrome P450 slow metabolizers.

The H1-receptor antagonist, niaprazine, is a safe drug that has been used in children and adolescents with ASD and insomnia.

\section{Conclusion}

Sleep disturbances in children and adolescents with ASD are frequent and can negatively affect their lives and developmental processes, and the life and emotional well-being of their families. Sleep disturbance has a significant negative impact on their daytime functioning and harms the quality of life of children and adolescents with ASD and their families by exacerbating externalizing and internalizing problem behaviors. Therefore, we must recog- nize sleep disturbances early and manage them actively. Sleep disturbances in children and adolescents with ASD may be caused by environmental problems, sensory hyper-arousal, circadian gene abnormalities, melatonin system abnormalities, and accompanying psychiatric disorders. Detailed history taking is required to evaluate sleep disturbance, and a sleep questionnaire can be used as an adjunct. To treat sleep disturbance in children and adolescents with ASD, non-pharmacological management, such as environmental control and CBT, should be prioritized. Medications should be started only if necessary with low doses, and side effects should be closely monitored. The importance of sleep disturbance in ASD must be recognized and the quality of life of patients and their families must be ensured through early and active interventions. Additionally, ongoing research on the causes of sleep disturbance and effective treatment methods is anticipated to continue in children and adolescents with ASD.

\section{Notes}

\section{Conflicts of interest}

No potential conflict of interest relevant to this article was reported.

\section{ORCID}

Wan Seok Seo, https://orcid.org/0000-0002-5122-5360

\section{References}

1. Hyman SL, Levy SE, Myersh SM; Council on Children with Disabilities, Section on Developmental and Behavioral Pediatrics. Identification, evaluation, and management of children with autism spectrum disorder. Pediatrics 2020;145:e20193447.

2. Werling DM, Parikshak NN, Geschwind DH. Gene expression in human brain implicates sexually dimorphic pathways in autism spectrum disorders. Nat Commun 2016;7:10717.

3. Eapen V, Crnčec R, Walter A. Clinical outcomes of an early intervention program for preschool children with Autism Spectrum Disorder in a community group setting. BMC Pediatr 2013;13:3.

4. Hirata I, Mohri I, Kato-Nishimura K, Tachibana M, Kuwada A, Kagitani-Shimono K, et al. Sleep problems are more frequent and associated with problematic behaviors in preschoolers with autism spectrum disorder. Res Dev Disabil 2016;49-50:86-99.

5. Buckley AW, Rodriguez AJ, Jennison K, Buckley J, Thurm A, Sato $S$, et al. Rapid eye movement sleep percentage in children with autism compared with children with developmental delay and typical development. Arch Pediatr Adolesc Med 2010;164: 
$1032-7$.

6. Hodge D, Carollo TM, Lewin M, Hoffman CD, Sweeney DP. Sleep patterns in children with and without autism spectrum disorders: developmental comparisons. Res Dev Disabil 2014;35:1631-8.

7. Malow BA, Crowe C, Henderson L, McGrew SG, Wang L, Song Y, et al. A sleep habits questionnaire for children with autism spectrum disorders. J Child Neurol 2009;24:19-24.

8. Richdale AL, Schreck KA. Sleep problems in autism spectrum disorders: prevalence, nature, \& possible biopsychosocial aetiologies. Sleep Med Rev 2009;13:403-11.

9. Mazurek MO, Sohl K. Sleep and behavioral problems in children with autism spectrum disorder. J Autism Dev Disord 2016;46:1906-15.

10. Cohen S, Conduit R, Lockley SW, Rajaratnam SM, Cornish KM. The relationship between sleep and behavior in autism spectrum disorder (ASD): a review. J Neurodev Disord 2014;6: 44.

11. Hollway JA, Aman MG. Sleep correlates of pervasive developmental disorders: a review of the literature. Res Dev Disabil 2011;32:1399-421.

12. Elrod MG, Hood BS. Sleep differences among children with autism spectrum disorders and typically developing peers: a meta-analysis. J Dev Behav Pediatr 2015;36:166-77.

13. Kotagal S, Broomall E. Sleep in children with autism spectrum disorder. Pediatr Neurol 2012;47:242-51.

14. Adkins KW, Molloy C, Weiss SK, Reynolds A, Goldman SE, Burnette C, et al. Effects of a standardized pamphlet on insomnia in children with autism spectrum disorders. Pediatrics 2012;130(Suppl 2):S139-44.

15. Sikora DM, Johnson K, Clemons T, Katz T. The relationship between sleep problems and daytime behavior in children of different ages with autism spectrum disorders. Pediatrics 2012; 130(Suppl 2):S83-90.

16. Adams HL, Matson JL, Jang J. The relationship between sleep problems and challenging behavior among children and adolescents with autism spectrum disorder. Res Autism Spectr Disord 2014;8:1024-30.

17. Lindor E, Sivaratnam C, May T, Stefanac N, Howells K, Rinehart N. Problem behavior in autism spectrum disorder: considering core symptom severity and accompanying sleep disturbance. Front Psychiatry 2019;10:487.

18. Malow BA, Marzec ML, McGrew SG, Wang L, Henderson LM, Stone WL. Characterizing sleep in children with autism spectrum disorders: a multidimensional approach. Sleep 2006;29: 1563-71.

19. Goldman SE, Surdyka K, Cuevas R, Adkins K, Wang L, Malow
BA. Defining the sleep phenotype in children with autism. Dev Neuropsychol 2009;34:560-73.

20. Cohen S, Fulcher BD, Rajaratnam SM, Conduit R, Sullivan JP, St Hilaire MA, et al. Sleep patterns predictive of daytime challenging behavior in individuals with low-functioning autism. Autism Res 2018;11:391-403.

21. Souders MC, Mason TB, Valladares O, Bucan M, Levy SE, Mandell DS, et al. Sleep behaviors and sleep quality in children with autism spectrum disorders. Sleep 2009;32:1566-78.

22. Bourgeron T. The possible interplay of synaptic and clock genes in autism spectrum disorders. Cold Spring Harb Symp Quant Biol 2007;72:645-54.

23. Tordjman S, Najjar I, Bellissant E, Anderson GM, Barburoth M, Cohen D, et al. Advances in the research of melatonin in autism spectrum disorders: literature review and new perspectives. Int J Mol Sci 2013; 14:20508-42.

24. Foley LS, Maddison R, Jiang Y, Marsh S, Olds T, Ridley K. Presleep activities and time of sleep onset in children. Pediatrics 2013;131:276-82.

25. Engelhardt CR, Mazurek MO, Sohl K. Media use and sleep among boys with autism spectrum disorder, $\mathrm{ADHD}$, or typical development. Pediatrics 2013;132:1081-9.

26. Waddington H, McLay L, Woods L, Whitehouse AJ. Child and family characteristics associated with sleep disturbance in children with autism spectrum disorder. J Autism Dev Disord 2020;50:4121-32.

27. Martin CA, Papadopoulos N, Chellew T, Rinehart NJ, Sciberras E. Associations between parenting stress, parent mental health and child sleep problems for children with ADHD and ASD: systematic review. Res Dev Disabil 2019;93:103463.

28. Bonnet MH, Arand DL. Hyperarousal and insomnia: state of the science. Sleep Med Rev 2010;14:9-15.

29. Healey ES, Kales A, Monroe LJ, Bixler EO, Chamberlin K, Soldatos CR. Onset of insomnia: role of life-stress events. Psychosom Med 1981;43:439-51.

30. Morin CM, Rodrigue S, Ivers H. Role of stress, arousal, and coping skills in primary insomnia. Psychosom Med 2003;65:25967.

31. Valentino RJ, Van Bockstaele E. Convergent regulation of locus coeruleus activity as an adaptive response to stress. Eur J Pharmacol 2008;583:194-203.

32. Reynolds S, Lane SJ, Thacker L. Sensory processing, physiological stress, and sleep behaviors in children with and without autism spectrum disorders. OTJR (Thorofare NJ) 2012;32:24657.

33. Mazurek MO, Petroski GF. Sleep problems in children with autism spectrum disorder: examining the contributions of sensory 
over-responsivity and anxiety. Sleep Med 2015;16:270-9.

34. Wimpory D, Nicholas B, Nash S. Social timing, clock genes and autism: a new hypothesis. J Intellect Disabil Res 2002;46(Pt 4):352-8.

35. Veatch OJ, Keenan BT, Gehrman PR, Malow BA, Pack AI. Pleiotropic genetic effects influencing sleep and neurological disorders. Lancet Neurol 2017;16:158-70.

36. Veatch OJ, Veenstra-Vanderweele J, Potter M, Pericak-Vance MA, Haines JL. Genetically meaningful phenotypic subgroups in autism spectrum disorders. Genes Brain Behav 2014;13: 276-85.

37. Yang Z, Matsumoto A, Nakayama K, Jimbo EF, Kojima K, Nagata $\mathrm{K}$, et al. Circadian-relevant genes are highly polymorphic in autism spectrum disorder patients. Brain Dev 2016;38:91-9.

38. Carmassi C, Palagini L, Caruso D, Masci I, Nobili L, Vita A, et al. Systematic review of sleep disturbances and circadian sleep desynchronization in autism spectrum disorder: toward an integrative model of a self-reinforcing loop. Front Psychiatry 2019; 10:366.

39. Veatch OJ, Pendergast JS, Allen MJ, Leu RM, Johnson CH, Elsea $\mathrm{SH}$, et al. Genetic variation in melatonin pathway enzymes in children with autism spectrum disorder and comorbid sleep onset delay. J Autism Dev Disord 2015;45:100-10.

40. Melke J, Goubran Botros H, Chaste P, Betancur C, Nygren G, Anckarsäter $\mathrm{H}$, et al. Abnormal melatonin synthesis in autism spectrum disorders. Mol Psychiatry 2008;13:90-8.

41. Mulder EJ, Anderson GM, Kemperman RF, Oosterloo-Duinkerken A, Minderaa RB, Kema IP. Urinary excretion of 5-hydroxyindoleacetic acid, serotonin and 6-sulphatoxymelatonin in normoserotonemic and hyperserotonemic autistic individuals. Neuropsychobiology 2010;61:27-32.

42. Kerns CM, Kendall PC, Berry L, Souders MC, Franklin ME, Schultz RT, et al. Traditional and atypical presentations of anxiety in youth with autism spectrum disorder. J Autism Dev Disord 2014;44:2851-61.

43. Yerys BE, Wallace GL, SokoloffJL, Shook DA, James JD, Kenworthy L. Attention deficit/hyperactivity disorder symptoms moderate cognition and behavior in children with autism spectrum disorders. Autism Res 2009;2:322-33.

44. Panju S, Brian J, Dupuis A, Anagnostou E, Kushki A. Atypical sympathetic arousal in children with autism spectrum disorder and its association with anxiety symptomatology. Mol Autism 2015;6:64.

45. Ibáñez V, Silva J, Cauli O. A survey on sleep questionnaires and diaries. Sleep Med 2018;42:90-6.

46. Owens JA, Spirito A, McGuinn M. The Children's Sleep Habits
Questionnaire (CSHQ): psychometric properties of a survey instrument for school-aged children. Sleep 2000;23:1043-51.

47. Aman MG, Singh NN, Stewart AW, Field CJ. The aberrant behavior checklist: a behavior rating scale for the assessment of treatment effects. Am J Ment Defic 1985;89:485-91.

48. Malow BA, Byars K, Johnson K, Weiss S, Bernal P, Goldman SE, et al. A practice pathway for the identification, evaluation, and management of insomnia in children and adolescents with autism spectrum disorders. Pediatrics 2012;130(Suppl 2):S10624.

49. Malow BA, Adkins KW, Reynolds A, Weiss SK, Loh A, Fawkes $D$, et al. Parent-based sleep education for children with autism spectrum disorders. J Autism Dev Disord 2014;44:216-28.

50. Andersen IM, Kaczmarska J, McGrew SG, Malow BA. Melatonin for insomnia in children with autism spectrum disorders. J Child Neurol 2008;23:482-5.

51. Gringras P, Green D, Wright B, Rush C, Sparrowhawk M, Pratt $\mathrm{K}$, et al. Weighted blankets and sleep in autistic children: a randomized controlled trial. Pediatrics 2014;134:298-306.

52. Frazier TW, Krishna J, Klingemier E, Beukemann M, Nawabit $\mathrm{R}$, Ibrahim S. A randomized, crossover trial of a novel sound-tosleep mattress technology in children with autism and sleep difficulties. J Clin Sleep Med 2017; 13:95-104.

53. Malow BA, Katz T, Reynolds AM, Shui A, Carno M, Connolly $H V$, et al. Sleep difficulties and medications in children with autism spectrum disorders: a registry study. Pediatrics 2016; 137(Suppl 2):S98-104.

54. Gringras P, Nir T, Breddy J, Frydman-Marom A, Findling RL. Efficacy and safety of pediatric prolonged-release melatonin for insomnia in children with autism spectrum disorder.J Am Acad Child Adolesc Psychiatry 2017;56:948-57.

55. Cortesi F, Giannotti F, Sebastiani T, Panunzi S, Valente D. Controlled-release melatonin, singly and combined with cognitive behavioural therapy, for persistent insomnia in children with autism spectrum disorders: a randomized placebo-controlled trial. J Sleep Res 2012;21:700-9.

56. Rossignol DA, Frye RE. Melatonin in autism spectrum disorders: a systematic review and meta-analysis. Dev Med Child Neurol 2011;53:783-92.

57. Fiks AG, Mayne SL, Song L, Steffes J, Liu W, McCarn B, et al. Changing patterns of alpha agonist medication use in children and adolescents 2009-2011.J Child Adolesc Psychopharmacol 2015;25:362-7.

58. Golubchik P, Sever J, Weizman A. Low-dose quetiapine for adolescents with autistic spectrum disorder and aggressive behavior: open-label trial. Clin Neuropharmacol 2011;34:216-9. 